Original Research Article

\title{
Cross sectional study on different doses of acenocoumarol with INR in a tertiary care hospital
}

\author{
Keerthi E. ${ }^{1}$, Bhuvaneshwari S. ${ }^{2 *}$, Periyanarkunan Ramaiya Murugesan ${ }^{3}$, \\ Priyadharshini T. ${ }^{1}$, Sri Subiksha P. ${ }^{1}$
}

\author{
${ }^{1}$ MBBS Student, PSGIMS\&R, \\ Coimbatore, Tamil Nadu, India \\ ${ }^{2}$ Department of Pharmacology, \\ KFMSR, Coimbatore, Tamil \\ Nadu, India \\ ${ }^{3}$ Department of Cardiothoracic \\ Surgery, PSGIMS\&R, \\ Coimbatore, Tamil Nadu, India
}

Received: 22 June 2018 Accepted: 26 July 2018

*Correspondence to:

Dr. Bhuvaneshwari S., Email: bhuvana1421@ gmail.com

Copyright: (C) the author(s), publisher and licensee Medip Academy. This is an openaccess article distributed under the terms of the Creative Commons Attribution NonCommercial License, which permits unrestricted noncommercial use, distribution, and reproduction in any medium, provided the original work is properly cited.

\begin{abstract}
Background: It is of high value to be assess the relationship between doses of Acenocoumarol and the INR values to offer better patient care. Since Acenocoumarol is a commonly used drug with a narrow therapeutic range it is essential to monitor the variations encountered in response to it to avoid drastic complications and to provide better health care. Aim: The aim of this study is to compare the INR values with different doses of Acenocoumarol, to compare the association of dose of Acenocoumarol with their respective INR and to find out the occurrence of bleeding with different doses of Acenocoumarol.

Methods: The study was conducted in a Tertiary care hospital. 40 patients taking Acenocoumarol were recruited in the study. Relevant details like age, weight, dose of Acenocoumarol, INR and other concomitant drugs were obtained in a prospective manner. Correlation of dose of Acenocoumarol with respective INR was done by simple linear regression.

Results: The relationship between dose and INR was analyzed using Simple linear regression and the scatter plot revealed no significant correlation between the dose and INR values. There is a lot of inter-individual variability in the dose response and thereafter the INR values.

Conclusions: The dose of Acenocoumarol cannot predict INR values. Patient can ideally be started treatment on a low dose of Acenocoumarol and based on the INR values, dose can be titrated. There is a need for consideration of other factors which influence the dose and INR values.
\end{abstract}

Keywords: Acenocoumarol, Different doses, INR

\section{INTRODUCTION}

Acenocoumarol is an oral anticoagulant used for the prevention and treatment of thromboembolic disorders (atrial fibrillation, cardiac valve replacement, after myocardial infarction, treatment of deep vein thrombosis and after major surgeries). It is a momo-coumarin derivative and a vitamin $\mathrm{K}$ antagonist. It acts by inhibiting Vitamin $\mathrm{K}$ epoxide reductase and thus inhibits the synthesis of vitamin $\mathrm{K}$ dependent clotting factors such as 2, 7, 9, 10 and also endogenous anticoagulants like Protein $\mathrm{C}$ and Protein S. ${ }^{1}$ Acenocoumarol is effective and safe to be used in patients of all age groups. But due to differing sensitivity to its anticoagulant effect, the dose is individualized based on the age and INR of the patient. ${ }^{2}$ Acenocoumarol is usually administered as once daily oral dose given at the same time every day. Recommended therapeutic range for oral anticoagulant therapy with Acenocoumarol is: 2-3.5. ${ }^{3}$ Appropriate dosing of Acenocoumarol is difficult to establish, due to widespread inter-individual variability in its pharmacokinetics and pharmacodynamic responses and its narrow therapeutic window. Numerous genetic and non-genetic factors have 
been associated with the inter-individual variability in Acenocoumarol dosing requirements.

Patients start with daily doses of about $2 \mathrm{mg}$, and thereafter the dose is adjusted in accordance with INR test results. Numerous factors have been associated with the Acenocoumarol dose required to obtain stable anticoagulation, including age, gender, weight, height, drug interactions and variations in the VKORC1 and CYP2C9 genes. Also, inappropriate use of vitamin $\mathrm{K}$, inconsistent overlapping of heparin with Acenocoumarol, inconsistent provision of patient education also results in variations in response. ${ }^{4}$

Hence it is of high value to be assess the relationship between doses of Acenocoumarol and the INR values to offer better patient care. Since Acenocoumarol is a commonly used drug with a narrow therapeutic range it is essential to monitor the variations encountered in response to it to avoid drastic complications and to provide better health care.

The aim of this study is to compare the INR values with different doses of Acenocoumarol; to compare the association of dose of Acenocoumarol with their respective INR and to find out the occurrence of bleeding with different doses of Acenocoumarol.

\section{METHODS}

A cross sectional study was conducted in a Tertiary care hospital in TamilNadu after approval from Institutional Human Ethics Committee. 40 patients taking Acenocoumarol for more than 3 months, with normal liver function and under Vitamin $\mathrm{K}$ restricted diet were recruited for the study. The study was conducted between August and December of 2017.

Known cases of Major illness which leads to coagulation disturbance(Hemophilia,Factor5 Leiden mutation, Protein C deficiency, Protein S deficiency, Von Willebrand's disease, cirrhosis, Shock, Sepsis, Malignancy, Renal disease, Anti-phospholipid antibody syndrome, Systemic Lupus Erythematosus) and patients on drugs which are known to produce interactions with Acenocumarol (Allopurinol, Amiodarone, Azathioprine, Betamethasone, Carbamazepine, Cefoxitin , Cholestyramine, Cimetidine, Dexmethasone, Doxycycline, Erythromycin, Fenofibrate, Fluvostatin, Gingko biloba, Ibuprofen, Ketoconazole, Lovastatin, Orlistat, Quinine, Zafirlukast) were excluded from the study.

Patients with various diseases like Valvular heart disease, Atrial fibrillation, Deep vein thrombosis, Aortic stenosis and several related conditions which have risk of thrombus formation and embolisation were chosen for the study. Relevant details like age, weight, dose of Acenocoumarol, INR and other concomitant drugs were obtained in a prospective manner.
Correlation of dose of Acenocumarol with respective INR was done by simple linear regression. A P Value of $<0.05$ is considered as significant.

\section{RESULTS}

Of the 40 patients who were on Acenocoumarol, 62.5\% were males and $37.5 \%$ were females and the mean INR for males and females was calculated. It was found to be 2.02 and 3.16 (Table 1).

Table 1: Percentage of male and female in the study.

\begin{tabular}{|llll|}
\hline Gender & $\begin{array}{l}\text { Number } \\
\text { (total = 40) }\end{array}$ & percentage & $\begin{array}{l}\text { Average } \\
\text { INR }\end{array}$ \\
\hline Male & 25 & $62.5 \%$ & 2.02 \\
\hline Female & 15 & $37.5 \%$ & 3.16 \\
\hline
\end{tabular}

Also, the mean INR values for different age groups were calculated. It was more (2.82) with 41-50 years of age group and less (1.33) with 31-40 years of age group (Table 2).

Table 2: Percentage of different age groups in the study.

\begin{tabular}{|llll|}
\hline $\begin{array}{l}\text { Age } \\
\text { group }\end{array}$ & $\begin{array}{l}\text { No. of } \\
\text { patients }\end{array}$ & $\begin{array}{l}\text { Percentage } \\
\text { of patients } \\
(\%)\end{array}$ & $\begin{array}{l}\text { Average INR } \\
\text { for this age } \\
\text { group }\end{array}$ \\
\hline $11-20$ & 1 & 2.5 & 1.87 \\
\hline $21-30$ & 4 & 10 & 3.15 \\
\hline $31-40$ & 3 & 7.5 & 1.33 \\
\hline $41-50$ & 13 & 32.5 & 2.82 \\
\hline $51-60$ & 14 & 35 & 2.40 \\
\hline $61-70$ & 5 & 12.5 & 1.82 \\
\hline
\end{tabular}

Table 3: Comparison of fixed dose with INR values.

\begin{tabular}{|llll|}
\hline $\begin{array}{l}\text { Dose } \\
(\mathbf{m g})\end{array}$ & $\begin{array}{l}\text { No. of patients } \\
\text { receiving this } \\
\text { dose }\end{array}$ & $\begin{array}{l}\text { Percentage } \\
(\%)\end{array}$ & $\begin{array}{l}\text { Average } \\
\text { INR for } \\
\text { this dose }\end{array}$ \\
\hline 1 & 6 & 15 & 2.03 \\
\hline 1.5 & 1 & 2.5 & 1.54 \\
\hline 2 & 14 & 35 & 3.08 \\
\hline 2.5 & 3 & 7.5 & 2.64 \\
\hline 3 & 5 & 12.5 & 2.4 \\
\hline 3.5 & 1 & 2.5 & 1.44 \\
\hline 4 & 7 & 17.5 & 1.99 \\
\hline 5 & 2 & 5 & 1.44 \\
\hline 6 & 1 & 2.5 & 2.65 \\
\hline
\end{tabular}

Keeping the dose of Acenocoumarol fixed, INR values in different patients were considered and a mean INR was calculated for each fixed dose. $35 \%$ of patients were prescribed with $2 \mathrm{mg}$ of dose of Acenocoumarol. Only $1 \%$ of patients were prescribed $1.5 \mathrm{mg}, 3.5 \mathrm{mg}$ and $6 \mathrm{mg}$ of Acenocoumarol. Mean INR was high (3.08) with $2 \mathrm{mg}$ dose of Acenocoumarol. Mean INR was low (1.44) with 
$3.5 \mathrm{mg}$ and $5 \mathrm{mg}$ of Acenocoumarol. Lowest dose (1mg) of Acenocoumarol was producing Mean INR of 2.03 and Highest dose of Acenocoumarol $(6 \mathrm{mg})$ was producing mean INR of 2.65. A patient receiving $1 \mathrm{mg}$ of Acenocoumarol had a higher INR value of 3.65 than patient receiving $5 \mathrm{mg}$ dose whose INR was 1.83 . (Table 3). Also, the mean dose of Acenocoumarol for each fixed range of INR was calculated. Average dose for low (1.7mg) with INR range of 3-3.99. Average dose is high (3.04 mg) with INR dose rang of 2-2.99. Lowest INR range was seen $4 \mathrm{mg}$ average dose of Acenocoumarol. Highest INR range (12-13) was seen with $2 \mathrm{mg}$ dose of Acenocoumarol (Table 4).

Table 4: Comparison of fixed INR range with dose.

\begin{tabular}{|llll|}
\hline $\begin{array}{l}\text { INR } \\
\text { range }\end{array}$ & $\begin{array}{l}\text { No. of } \\
\text { patients } \\
\text { with this } \\
\text { INR }\end{array}$ & $\begin{array}{l}\text { Percentage } \\
\text { of patients }\end{array}$ & $\begin{array}{l}\text { Average } \\
\text { dose for } \\
\text { this INR in } \\
\text { mg }\end{array}$ \\
\hline $0.1-0.99$ & 2 & 5 & 4 \\
\hline $1-1.99$ & 18 & 45 & 2.47 \\
\hline $2-2.99$ & 11 & 27.5 & 3.04 \\
\hline $3-3.99$ & 5 & 12.5 & 1.7 \\
\hline $4-4.99$ & 3 & 7.5 & 3 \\
\hline $12-13$ & 1 & 2.5 & 2 \\
\hline
\end{tabular}

The relationship between dose and INR was also analysed using Simple linear regression and the scatter plot reveals no significant correlation between the dose and INR values by SPSS software (Figure 1). The P value obtained in the study was 0.5074 .

There were no episodes of bleeding with Acenocoumarol noted.

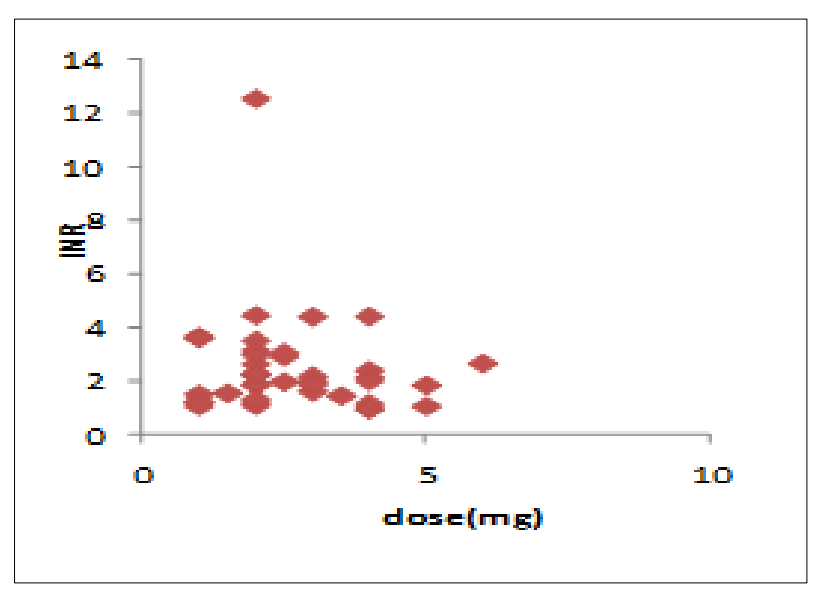

Figure 1: Simple linear regression scatter plot.

\section{DISCUSSION}

It has been found that acenocoumarol requirements decrease with aging, showing a gradual decline from 30 to 80 years. $^{7}$ This is important in choosing the initial dose. The study suggests dose cannot predict INR values (Figure
1). There is a lot of inter-individual variability in the dose response and thereafter the INR values. For example, a patient receiving $1 \mathrm{mg}$ Acenocoumarol had a higher INR value of 3.65 than patient receiving $5 \mathrm{mg}$ dose whose INR was 1.83 . So, there is a strong need for consideration of other factors which influence the dose and INR values.

A similar study in Netherlands concluded that patient characteristics such as age and body size influence the dose requirements. Also, genetic factors, notably polymorphisms in the $V K O R C 1$ gene which expresses vitamin $\mathrm{K}$ epoxide reductase (the main target for coumarins) and the $C Y P 2 C 9$ gene which expresses cytochrome P450 2C9 (the enzyme responsible for the metabolism of coumarin), together have been shown to explain $35-50 \%$ of the inter-individual variability in dose requirement. It is ideal that all patients receive a standard loading dose at the start of the therapy, which is subsequently adjusted to an individual maintenance dose according to the measured INR.

Numerous factors have been associated with the Acenocoumarol dose required to obtain stable anticoagulation, including age, gender, weight, height, drug interactions and variations in the VKORCl and CYP2C9 genes. Also, inappropriate use of vitamin $\mathrm{K}$, inconsistent overlapping of heparin with Acenocoumarol, inconsistent provision of patient education also results in variations in response. ${ }^{8}$

A study done in Spanish patients, have developed the first pharmacogenetic dosing algorithm for acenocoumarol including clinical variables and information about four genes (VKORC1, CYP2C9, CYP4F2 and APOE) and which can able to reasonably predict stable therapeutic doses of acenocoumarol for patients with thromboembolic disease. ${ }^{9}$ A similar study conducted in north India specified pharmacogenetic acenocoumarol dosing algorithm which might become a baseline for personalized medicine approach for treatment of patients in future. ${ }^{10}$

The variation in dose response and INR values might be due to underlying genetic predisposition. Further exploration on this aspect requires studies with larger sample size and availability of PCR techniques to explore genetic polymorphism.

\section{CONCLUSION}

The dose of Acenocoumarol cannot predict INR values. There is a lot of inter individual variation with regard to dose response and INR values. Patient can ideally be started treatment on a low dose of Acenocoumarol and based on the INR values, dose can be titrated.

\section{Funding: No funding sources}

Conflict of interest: None declared

Ethical approval: The study was approved by the Institutional Ethics Committee 


\section{REFERENCES}

1. Barcellona D, Vannini ML, Fenu L, Balestrieri C, Marongiu F. Warfarin or acenocoumarol: which is better in the management of oral anticoagulants. Thrombosis and Haemostasis-Stuttgart. 1998 Dec 1;80:899-902.

2. Trailokya A, Hiremath JS, Sawhney J, Mishra YK, Kanhere V, Srinivasa R, et al. Acenocoumarol: A Review of Anticoagulant Efficacy and Safety. The J Asso of Physici of Indi. 2016 Feb;64(2):88-93.

3. Hirsch J, Dalen JE, Deykin D, Poller L. Oral anticoagulants: mechanism of action, clinical effectiveness, and optimal therapeutic range. Chest. 1992 Oct $1 ; 102(4): 312 S$.

4. Mekaj YH, Mekaj AY, Duci SB, Miftari EI. New oral anticoagulants: their advantages and disadvantages compared with vitamin $\mathrm{K}$ antagonists in the prevention and treatment of patients with thromboembolic events. Therapeutics and clinical risk management. 2015;11:967.

5. Harder S, Thürmann P. Clinically important drug interactions with anticoagulants. Clinical pharmacokinetics. 1996 Jun 1;30(6):416-44.

6. Becquemont L. Evidence for a pharmacogenetic adapted dose of oral anticoagulant in routine medical practice. Eur J Clin Pharmacol. 2008 Oct 1;64(10):953.
7. Cesar JM, García-Avello A, Navarro JL, Herraez MV. Aging and oral anticoagulant therapy using acenocoumarol. Blood coagulation and fibrinolysis. 2004 Dec 1;15(8):673-6.

8. Van Schie RM, Wessels JA, le Cessie S, de Boer A, Schalekamp T, van der Meer FJ, et al. EU-PACT Study Group. Loading and maintenance dose algorithms for phenprocoumon and acenocoumarol using patient characteristics and pharmacogenetic data. Eur Heart J. 2011 Jun 2;32(15):1909-17.

9. Borobia AM, Lubomirov R, Ramírez E, Lorenzo A, Campos A, Muñoz-Romo R, et al. An acenocoumarol dosing algorithm using clinical and pharmacogenetic data in Spanish patients with thromboembolic disease. PLoS One. 2012 Jul 20;7(7):e41360.

10. Rathore SS, Agarwal SK, Pande S, Singh SK, Mittal T, Mittal B. Therapeutic dosing of acenocoumarol: proposal of a population specific pharmacogenetic dosing algorithm and its validation in north Indians. PLoS One. 2012 May 22;7(5):e37844.

Cite this article as: Keerthi E, Bhuvaneshwari $\mathrm{S}$, Murugesan PR, Priyadharshini T, Sri Subiksha P. Cross sectional study on different doses of acenocoumarol with INR in a tertiary care hospital. Int J Basic Clin Pharmacol 2018;7:1738-41. 